\title{
Recuerdo de José Antonio Ramos
}

\author{
Conocí a José Antonio Ramos en el año de 1932. Desde entonces \\ tuvimos una amistad ininterrumpida que sólo la muerte ha po- \\ dido truncar. \\ Mi buen amigo, el escritor Guillermo Jiménéz y yo, trabajába- \\ mos en el Departamento de Bibliotecas de la Secretaría de Educación \\ Pública, él como Director de la Revista Bibliográfica El libro y el \\ Pueblo, una importantísima publicación literaria en la que colaboraron \\ los más eminentes escritores del país y del extranjero, que por des- \\ gracia se suspendió, y yo dirigía el Volante de El libro y el Pueblo, \\ una modesta revista popular de divulgación para obreros, campe- \\ sinos y estudiantes en general. \\ Guillermo y yo hablábamos a menudo de teatro. En aquella épo- \\ ca, ya que ahora las circuñstancias me han modificado un poco, era \\ yo una enamorada fanática del teatro de drama y connedia de auto- \\ res mexicanos, y él procuraba darme gusto en este sentido, trayendo \\ a colación todo aquello que pudiera interesarme. Unà mañana \\ me dijo:
}

- Acaba de llegar una persona muy interesante. Es un escritor cubano, dramaturgo de altos vuelos; gran revolucionario y patriota. Viene desterrado de sú país por la dictadura machadista. Tendré mucho gusto en presentárselo. Creo que harán muy buenas migas.

Esperé con ansiedad los días que pasaron sin que se presentara este personaje. Mi curiosidad no podía más. Estaba sobre ascuas. Cierto día, me topé de manos a boca con un hombre ni muy alto ni muy bajo; fornido, nervioso, apasionado en el habla y en el pensamiento. Agil de cuerpo y de espíritu; juvenil, atrayente, que hablaba de su país con un fuego inusitado y que cautivaba con la 
magia de su palabra. Era José Antonio Ramos. Creo que nadie nos presentó. Nos encontramos frente a frente, él hablándome de Guillermo Jiménez, y yo deseosa de averiguar quién era el que así me hablaba de Guillermo.

Nos presentamos mutuamente, nos estrechamos la mano y principiamos a charlar de lo que era tema favorito: el teatro. Me cautivó en seguida su entusiasmo y su fe en el porvenir. Hablaba con acento dolorido de las desgracias de su patria y emocionaba escuchar sus augurios para el futuro.

Nuestra amistad se inició desde el primer momento. Una corriente de viva simpatía mutua se estableció entre nosotros, de tal manera que estábamos identificados en gustos y tendencias.

Pasábamos horas interminables charlando de innumerables temas. Para José Antonio la augusta belleza de las ideas era como un vino fuerte cuya euforia to hacía delirar de entusiasmo; y se desbordaba, volcaba su alma de soñador en el torrente de palabras con que saludaba un libro, un hecho, un pensamiento.

Para él las Américas eran el emporio de la nueva civilización. En ellas debía germinar, en un futuro más o menos próximo, la semilla del hombre nuevo.

- Mi Colonterra - decía-, porque es un error llamarla América, se trata de un fraude que se le hizo a Colón, es la tierra de la esperanza; la tierra del porvenir, la de las grandes alboradas de la humanidad. En ella todo está virgen: desde los sentimientos y las emociones, hasta las ideas generales y los conceptos científicos y estéticos. De aquí saldrán las nuevas normas que rijan al mundo.

Ahora me doy cuenta de que, con clara visión, se adelantaba a los acontecimientos que le van dando la razón.

Nuestro pasatiempo favorito era el pasear por las calles de la ciudad. El lo observaba todo y hacía comentarios agudos sobre los temas que la realidad cotidiana nos iba dando. Al paso del hombre de la calle, de la mujer hogareña o trabajadora, del estudiante inquieto, de la muchacha romántica, su imaginación tejía historias apasionantes de muchos de ellos, y gozábamos un placer no igualado en este juego.

Uno de los temas que le preocupaban era la libertad más o menos real de que podía gozarse en nuestras repúblicas latinoamericanas. Se le encogía el corazón al pensar que Cuba, su Cuba, gemía bajo el yugo de la tiranía de Machado, y que tantos patriotas se agosta- 
ban en las mazmorras del Fuerte de la Cabaña o eran fusilados sin misericordia.

Me traslado a los días felices que pasé en La Habana el año pasado, y confieso que sólo hasta entonces, al compartir la vida de los cubanos; al darme cuenta de sus penas y de sus inquietudes; de sus problemas, de sus ansias y sus aspiraciones, hasta entonces, digo, he podido comprender la enorme desazón de José Antonio Ramos, su amargura y el dolor que laceraba su alma. Sólo hasta que aprendí a amar a Cuba por lo que vale, por lo que es y lo que ha sufrido, abarqué en toda su extensión el sentimiento que embargaba el alma de este hombre en aquellos días.

Pero no olvidábamos el teatro. El, como yo, era un enamorado de la escena. Recordaba cuando el actor español Tallaví representó una de sus obras. Con qué fruición contaba los incidentes, las situaciones; su estadía en España, sus aventuras y experiencias.

-No se comprende la verdadera misión del teatro, que es enseñar cautivando. Nuestros gobiernos, hechos a base de caudillaje, ignoran lo directa y certera que es la acción del teatro, porque si la conocieran, le prestarían una ayuda ilimitada. Desgraciadamente, exceptuando la Argentina, donde el teatro tiene ya categoría de arte propio, en nuestros demás países latinos de Colonterra está relegado a un último término. No es más que un arte infimo que sirve a los mercaderes sin escrúpulos para llenarse la bolsa y encanallarlo.

Hablaba del teatro como de un arte depurado; el arte más completo, pues en él entran la plástica, el sonido y el color; tres armonías que se funden en una sola para dar la impresión inolvidable de la vida.

Hablaba de sus obras con entusiasmo, pero sin perder de vista que su obra mejor, aquella en que pondría la selección de su intelecto, estaba por escribirla. Conocí escritas por él Las impurezas de la realidad, una novela de juventud de perfiles románticos y. un poco audaces. Tembladera y algunas otras que no recuerdo. Todas ellas llenas de generosa rebeldía, de un afán incontenible de superación; de huir de las realidades absurdas que el mundo le presentaba para refugiarse en la pureza de los sentimientos que siempre conducen hacia la libertad, una libertad integral hecha de respeto a la dignidad y a la vida humanas; de veneración a los sentimientos más delicados de la mujer que sabe darse en un gesto profundamente emotivo; de valoración de las más altas cualidades de la inteligen- 
cia, que es la única fuerza que salvará al mundo del caos y oprobio de las dictaduras.

José Antonio Ramos soñaba en voz alta sus más queridas utopías. Izquierdista de pensamiento austero y corazón generoso, pensaba que "el maquinismo" no debía convertirse en la ruina del hombre, sino en el mejor y más capaz sistema de liberación. Porque el hombre debe liberarse de la cadena del trabajo material agobiante para contemplar el porvenir inmenso que tiene ante sí: el campo amplísimo del desarrollo de la inteligencia, de sus facultades mentales, para servir mejor a sus semejantes y cumplir su destino histórico.

Una hermana mía, actriz, organizó bajo el patrocinio del Departamento de Bellas Artes de la Secretaría de Educación Pública, una temporada de teatro selecto en el antiguo Teatro Hidalgo, viejo coliseo de las calles de Regina de esta ciudad, que hasta entonces había sido el asilo predilecto de los dramas románticos que hicieron las delicias de nuestros abuelos.

José Antonio hirvió de entusiasmo.

-Ahora sí vamos a ver buen teatro -decía-. Lástima que no todo sea mexicano, pero en fin, tendremos oportunidad de ver a los Galsworthy, a los Shaw, Dostoiewsky y Strindberg. Algo es algo. Estamos atrasados un buen tiempo y conocer a los maestros de los pasados años es ya una ventaja.

Inmediatamente puso manos a la obra y en unos cuantos días nos dió la grata sorpresa de dedicarnos a mi hermana y a mí una obra teatral suya: En las manos de Dios.

En ella desenvuelve su preocupación favorita: el triunfo de la inteligencia sobre las obscuras fuerzas del mal y del obscurantismo. Hay en toda la obra un soplo apasionado de fuerzas en lucha. E1 día que en casa nos la leyó, quedamos llenos de entusiasmo. Por desgracia la temporada fué corta y no pudo llevarse a escena.

Se hizo costumbre que nos reuniéramos a leer en casa, periódicamente, algunas obras de teatro. Entre los concurrentes asiduos estaban José Antonio y Alfonso Gutiérrez Hermosillo, joven poeta de gran porvenir, que la muerte agostó en hora temprana.

Allí, en esas reuniones, conocimos algunas obras de Gutiérrez Hermosillo y otras varias. Nuestras charlas se dirigian a examinar la situación del teatro en México y cómo remediar sus deplorables condiciones. Mi hermana hacía esfuerzos sobrehumanos para sostenet su temporada a base de obras mexicanas y extranjeras y este 
trabajo ímprobo contaba con las simpatías y el consejo de José Antonio. Pasaba las horas asistiendo a los ensayos; iba casi diariamente a las funciones y más de una vez sostuvo enconadas disputas con los críticos por tal o cual detalle o concepto.

Nos acostumbramos a verlo como de la familia. Mi padre lo tenía en grande estima y yo lo consideraba uno de mis amigos predilectos.

Su situación económica era bastante precaria. Su condición de exiliado le restaba toda ayuda de los representantes de su país, y él, con una gran dignidad y un perfecto decoro, guardaba sus preocupaciones económicas para sólo sus amigos muy íntimos. Buscó acomodo en alguna casa comercial, una compañía, aun en el gobierno, pero pasaba el tiempo y nada práctico conseguía. Tenía algunas ideas comerciales que pensaba poner en práctica, pero tropezaba con la indiferencia y la incomprensión. Después de muchos esfuerzos vanos, logró un empleo que le permitió cierto desahogo y ya pudo dedicarse con más ahinco a sus trabajos literarios, sin la preocupación económica que lo trastornaba completamente. Lo que más le hacía sufrir en esta situación era la falta de elementos para comprar libros. Acostumbrado a largas lecturas, bien pronto devoró los de mi modesta biblioteca y los que le proporcionaban los amigos. En México los libros han sido siempre caros, y en ciertas condiciones son un lujo del que es preciso prescindir si se quiere atender necesidades más apremiantes, como a él le sucedía.

En aquella época se decidió a escribir su Panorama de la literatura norteamericana. Su conocimiento de ella era profundo. No en balde había sido profesor de la Universidad de Filadelfia, por largos: años. Valoraba la literatura norteamericana no sólo desde el punto de vista artístico, sino por su contenido ideológico y social. Contando con un nutrido material y con brillantísimas opiniones del autor, a pesar de sus grandes alientos, no le produjo cosa mayor ni material ni espiritualmente.

Sus amigos asistíamos a estas tragedias de su existencia impotentes para dar el remedio por nuestra mediocre situación. Cađa día nos identificábamos más con él, comprendiamos con mayor hondura: sus sinsabores, sus inquietudes y tristezas.

Pero el grande amigo que era José Antonio Ramos se agigantó cuando la tragedia visitó mi hogar. 
Una mañana, un viernes 21 de enero, llegó de visita a la redacción de El Libro y el Pueblo, como acostumbraba hacerlo a menudo. Guillermo Jiménez no estaba, así es que yo acaparé toda la conversación. Nos enredamos en amena charla. Los dos estábamos de un humor admirable. Llevaba a la mano un libro de Marcel Shwob que lo tenía fascinado. Me leyó algunos párrafos. Discutimos su contenido ideológico cuando sonó el teléfono. Me hablaban de mi casa para decirme que debía ir inmediatamente. porque mi padre se encontraba grave. No pude contener el asombro. Yo habia desayunado con él y lo encontré en perfecto estado de salud.

José Antonio trató de calmar mi preocupación.

-No es nada, no se alarme. Alguna indisposición que pasará. Yo la acompaño. Tomaremos un coche y la dejo en su casa.

Salimos de la Secretaría de Educación y nos dirigimos a mi casa en un coche de alquiler. En el trayecto él trataba de distraerme haciendo bromas, pero su empeño resultó inútil, porque yo tenía la corazonada de que algo grave sucedia.

En efecto, al llegar a casa me salió a encontrar el médico de la familia, antiguo amigo de mi padre, quien sin más preámbulos me dijo:

-Ten mucho valor ... acaba de morir tu papá.

Si un rayo hubiese caído a mis pies, no me habría hecho tanto efecto como estas palabras. Vacilé y José Antonio me sostuvo. Corrí al cuarto donde yacía el cadáver de mi padre y olvidé al buen amigo que se quedó solo en la sala, esperando. Permaneció allí hasta que mi dolor se desahogó un poco y me di cuenta de la situación. Había que poner telegramas para avisar a los familiares y amigos; que llamar por teléfono a los más cercanos; que comunicarse con la agencia de defunciones, los "comerciantes de la muerte", como los llamó este ilustre cubano. De todo ello se ocupó José Antonio con una diligencia extraordinaria que yo le agradecí con toda el alma.

Por la noche se reunieron los amigos y parientes a velar el cadáver, y él permaneció en nuestra compañía toda la noche, sin demostrar cansancio. El entierro fué a las cuatro de la tarde del día siguiente, y hasta esa hora nos estuvo acompañando.

Desde entonces se volvió más asiduo, más comprensivo. Me aconsejaba, me guiaba con mano segura y firme, y yo sentía en él un apoyo que me era muy necesario en las nuevas circunstancias en que se desenvolvía mi vida. 
No quisiera hablar de estas cosas, porque aún hoy que han pasado tantos años, me producen una desgarradura en el corazón; pero si debo recordar todo lo que la amistad de José Antonio Ramos significó para mí, necesariamente debo volver a aquellos tiempos en que la desgracia hincó su garra en mi hogar hasta destruirlo.

Apenas tranquilizada del dolor de la muerte de mi padre, ocurrió el deceso de mi madre. Para entonces había cambiado el gobierno machadista en Cuba y se habian abierto nuevos horizontes a José Antonio. Fué nombrado Cónsul General de su país en México, con residencia en Veracruz.

Pero no nos había alejado espiritualmente la ausencia. Nos escribíamos a menudo. Siempre me hablaba de que no había esfuerzo que se hiciese, por. grande que fuera, que el teatro no mereciera. Me animaba a luchar con ahinco por la gran causa a la que se sentía ligàdo por simpatía a mi país que consideraba también el suyo, y por amor a ella. Hizo muy a menudo viajes a esta ciudad en los que siempre iba a casa y me urgía a que le leyera "algo nuevo" o le contara lo que se hacía o se decía.

Poco a poco se fueron espaciando sus visitas. El trabajo del consulado lo absorbía completamente. Algún tiempo después me escribió alborozado que regresaba a la patria. Al fin se realizaba la ilusión que había acariciado por tanto tiempo. ¡Regresar a Cuba! Reanudar la vida interrumpida por el exilio. Hacía proyectos, soñaba. Sus cartas se hicieron más espaciadas y llegó el momento en que pasaron varios meses sin que tuviera noticias suyas. Supe que había sido nombrado Director de la Biblioteca del Departamento de Estado. En aquella época me escribió y me mandó su novela Caniquí, que es otra fogosa protesta contra la opresión y los prejuicios. Pasó una larga temporada sin que supiera nada de él. Me escribió al fin contándome que se casaba con una señorita poetisa a la que después tuve el gusto de conocer, durante mi estadía en La Habana.

Después de varios años tuve la oportunidad de conocer Cuba y de volver a ver al buen amigo. En él nada habia cambiado. Continuaba tan juvenil, tan fogoso y apasionado como siempre, y con más entusiasmos para la lucha por la vida, pues se sentía confortado por su bella y talentosa esposa, a la que también debo una amistad entrañable. 
Pasamos horas deliciosas en su casa en el último piso de un edificio que tenía vista para la bahía. Desde su ventana se miraban el Morro y La Cabaña.

Nos leyó su última obra, un canto al "hombre", a la humanidad; una formidable protesta contra los conceptos establecidos, contra los prejuicios comunes y la opresión del espíritu por creencias que, de tan viejas, parecen meros fantasmas; esqueletos de cosas muertas.

Aparentaba salud, se le veía en pleno dominio de sus facultades, impetuoso como siempre. Sostenía una lucha enconada con ciertos elementos de Cuba que no le reconocían sus méritos y el valor de su personalidad en la Dirección de la Biblioteca Nacional. Se sentía un poco herido, un poco desilusionado. El ambiente lo asfixiaba.

Tenía proyectado un viaje a los Estados Unidos para ampliar su Historia de la literatura norteamericana, y hacía planes para volver a México.

Una amiga común me dijo en cierta ocasión:

- Temo que no volverás a ver a José Antonio.

Me explicó que tenía la presión muy alta, que ya había sufrido amagos de apoplejía. Esto me entristeció, pero confié en su poderosa naturaleza. Sin embargo, nuestra amiga tenía razón. No lo volvi a ver. La muerte tronchó esa vida fecunda y exuberante. Cayó el luchador; se apagó la voz del vidente; el entusiasmo del patriota; la exquisitez del literato.

Descanse en paz.

María Luisa Ocampo 